\title{
Emission controls versus meteorological conditions in determining aerosol concentrations in Beijing during the 2008 Olympic Games
}

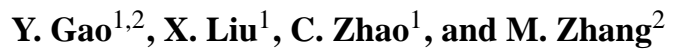 \\ ${ }^{1}$ Pacific Northwest National Laboratory, Richland, WA, USA \\ ${ }^{2}$ State Key Laboratory of Atmospheric Boundary Layer Physics and Atmospheric Chemistry (LAPC), \\ Institute of Atmospheric Physics, Chinese Academy of Sciences, Beijing, China \\ Received: 30 April 2011 - Published in Atmos. Chem. Phys. Discuss.: 14 June 2011 \\ Revised: 10 November 2011 - Accepted: 20 November 2011 - Published: 12 December 2011
}

\begin{abstract}
A series of emission control measures were undertaken in Beijing and the adjacent provinces in China during the 2008 Beijing Olympic Games on 8-24 August 2008. This provides a unique opportunity for investigating the effectiveness of emission controls on air pollution in Beijing. We conducted a series of numerical experiments over East Asia for the period of July to September 2008 using a coupled meteorology-chemistry model (WRF-Chem). Model can generally reproduce the observed variation of aerosol concentrations. Consistent with observations, modeled concentrations of aerosol species (sulfate, nitrate, ammonium, black carbon, organic carbon, total particulate matter) in Beijing were decreased by $30-50 \%$ during the Olympic period compared to the other periods in July and August in 2008 and the same period in 2007. Model results indicate that emission controls were effective in reducing the aerosol concentrations by comparing simulations with and without emission controls. In addition to emission controls, our analysis suggests that meteorological conditions (e.g. wind direction and precipitation) were also important in producing the low aerosol concentrations appearing during the Olympic period. Transport from the regions surrounding Beijing determined the daily variation of aerosol concentrations in Beijing. Based on the budget analysis, we suggest that to improve the air quality over Beijing, emission control strategy should focus on the regional scale instead of the local scale.
\end{abstract}

Correspondence to: X. Liu (xiaohong.liu@pnnl.gov)

\section{Introduction}

During the past three decades, the rapid economic growth in China has caused a significant increase in the emission of aerosols and precursor gases. This leads to highly elevated aerosol concentrations, especially in some mega-cities (e.g. Beijing and Shanghai) and Pearl River Delta Region (e.g. Q. Zhang et al., 2009; Chan and Yao, 2008). In these regions, particulate aerosol is the major cause of severe air pollution. Aerosol species including sulfate $\left(\mathrm{SO}_{4}\right)$, nitrate $\left(\mathrm{NO}_{3}\right)$, ammonium $\left(\mathrm{NH}_{4}\right)$, black carbon $(\mathrm{BC})$, organic carbon (OC), and dust could have significant impacts on environment and climate change in China (Tang et al., 2004; Han et al., 2008; Chan and Yao, 2008).

Beijing, China's capital city with a population of more than 16 millions, is one of the largest metropolises in the World. $\mathrm{PM}_{10}$ (Particle Matter of $10 \mu \mathrm{m}$ or less in the aerodynamic diameter) is reported to be the major cause of air pollution in Beijing on about $90 \%$ of days from 1999 to 2005 (Beijing Environmental Bulletin, 1994-2005) and its concentration exceeds the China's Grade-2 Standard (daily averaged concentration of $\mathrm{PM}_{10}$ of $150 \mu \mathrm{g} \mathrm{m}^{-3}$ ) on $30 \%$ of the days each year. While the emission control inside Beijing is a direct way to reduce the concentrations of air pollutants in Beijing, emissions in the regions surrounding Beijing can also significantly affect the air quality in Beijing because of the transport of primary aerosols and the formation of secondary aerosols in the downwind. For example, An et al. (2007) suggested that emissions over the northwest and southwest to Beijing contribute $39 \%$ and $15 \%$, respectively, to the particle matter concentrations over urban

Published by Copernicus Publications on behalf of the European Geosciences Union. 
Beijing. Streets et al. (2007) showed that $34 \%$ of $\mathrm{PM}_{2.5}$ (Particle Matter of $2.5 \mu \mathrm{m}$ or less in the aerodynamic diameter) and 35-60\% of ozone $\left(\mathrm{O}_{3}\right)$ in Beijing were transported from the regions surrounding Beijing based on simulations using the Community Multiscale Air Quality (CMAQ) model.

After being selected as the host of the 29th Olympic Games, the city government of Beijing has paid more attention to its air pollution problem. In order to achieve the goal that concentrations of sulfur dioxide $\left(\mathrm{SO}_{2}\right)$, nitrogen dioxide $\left(\mathrm{NO}_{2}\right)$, and $\mathrm{O}_{3}$ meet the standards suggested by the World Health Organization and concentrations of particulate matters meet the standards for the major cities of developed countries during the Olympic Games, City Government of Beijing implemented a series of emission control measures in Beijing and its surrounding regions prior to and during the Olympics (Report "29th Beijing Olympic Games Air Quality Safeguards" drafted by the Environmental Protection Agency of China et al.; M. Wang et al., 2009). Before the full-scale control (pre-20 July 2008), heavy industrial polluters (e.g. the Capital Steel Company) were relocated, and $50 \%$ of government cars were not allowed to drive in Beijing after 23 June 2008. During the full-scale control (from 20 July to 19 September 2008), first, the odd/even license plate number rule was applied on personal vehicles in Beijing; second, stricter control was applied on vehicles entering Beijing; third, the production of some factories that can cause air pollution was limited or even stopped. In addition, extra $20 \%$ government cars were not allowed to drive in Beijing, some outdoor constructions were stopped, and usages of coal-burning facilities were restricted during 8-24 August (the period of the Olympic Games) and 7-19 September (the period of the Paralympics). These measures offer a unique opportunity to investigate the effect of emission controls on the air quality in a mega-city. Several universities and research institutes in China had set up observation networks in Beijing and its surrounding provinces during the emission control period. Previous studies indicated that emission controls were effective in improving the air quality in Beijing in terms of reducing gas and aerosol concentrations during the Olympics (e.g. T. Wang et al., 2009; Cermak et al., 2009; Y. Wang et al., 2009; X.-Y. Zhang et al., 2009; Yang et al., 2011). Based on observed emission factors, S. Wang et al. (2010) estimated that emissions of aerosol precursors (e.g. $\mathrm{SO}_{2}$, nitrogen oxides $\left(\mathrm{NO}_{\mathrm{x}}\right)$, non-methane volatile organic compounds "NMVOCs") during the Olympic Games were reduced by about 40-60\% compared with those in June 2008. M. Wang et al. (2009) found that on-road concentrations of $\mathrm{NO}_{\mathrm{x}}, \mathrm{SO}_{2}$, carbon monoxide $(\mathrm{CO})$, and $\mathrm{BC}$ were reduced by $41 \%, 70 \%, 54 \%$, and $12 \%$, respectively during the Olympics, compared to those of the pre-control period (before 20 July 2008) from measurements by a mobile laboratory. The mean daytime $\mathrm{O}_{3}$ concentration was reduced by about $15 \mathrm{ppbv}$ and daytime $\mathrm{SO}_{2}, \mathrm{CO}$, and reactive oddnitrogen $\left(\mathrm{NO}_{y}\right)$ concentrations were reduced by $61 \%, 25 \%$, and $21 \%$, respectively, during the Olympic Games, com- pared to those of the same period in 2006 and 2007 from measurements at a rural site (Miyun site) of Beijing (Y. Wang et al., 2009).

As important as emissions, meteorological conditions can influence the air quality in mega-cities by affecting the chemical production of secondary pollutants in the atmosphere, wet/dry deposition of pollutants, and diffusion and exchange of pollutants with surrounding regions. Therefore, it is imperative to understand the role of meteorological conditions in determining the aerosol pollution during the Olympic Games. Some studies indicated that during the Olympic period, there were still high levels of air pollutants on some days, and unfavorable weather conditions were suggested to be the reason (e.g. T. Wang et al., 2010; X.-Y. Zhang et al., 2009). T. Wang et al. (2010) measured trace gases and aerosol prior to and during the Olympics and suggested that improved air quality during the Olympics has a clear relationship with weather conditions. X.-Y. Zhang et al. (2009) found that aerosol concentrations were still increased on some days during the Olympics due to the stabilized weather conditions. Previous studies examined the improvement of air quality in Beijing during the Olympic period by comparing to the pre-control periods or to the same periods in previous years. However, meteorological conditions (e.g. wind and precipitation) can be significantly different between these periods. There are no studies yet to examine the relative importance of emission controls versus weather conditions in determining the air quality change during the Olympics.

In this study, we investigate the changes in aerosol concentrations and factors determining these changes in Beijing during the Olympic Games, by using a coupled meteorologychemistry model (WRF-Chem). The contribution of emission controls versus weather condition changes is examined. We begin in Sect. 2 by introducing the WRF-Chem model and the numerical experiments conducted in this study. In Sect. 3, we give a description of observation data used in the model evaluation and result analysis. The variation of aerosol concentrations in Beijing during the Olympic Games and its relationship with emission controls and meteorology conditions are discussed in Sect. 4. Conclusions of this study are presented in Sect. 5.

\section{Model description}

\subsection{WRF-Chem model}

The model used in this study is the Weather Research and Forecasting model (WRF, version 3.2). WRF-Chem is a version of WRF that can simulate trace gases and aerosol simultaneously with the meteorological fields (Grell et al., 2005). There are two chemistry mechanisms in WRFChem: one is RADM2 (Regional Acid Deposition Model 2) photochemical mechanism (Stockwell et al., 1990) and 


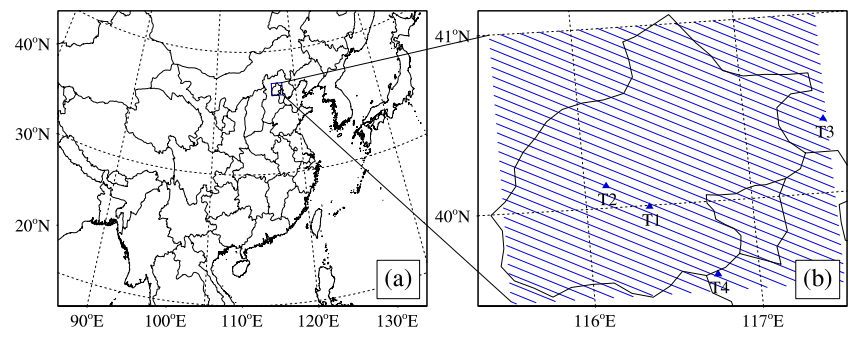

Fig. 1. Map of (a) the model simulation domain $\left(10^{\circ}-55^{\circ} \mathrm{N}\right.$, $\left.70^{\circ}-150^{\circ} \mathrm{E}\right)$ and (b) Beijing $\left(39.43^{\circ} \mathrm{N}-41.05^{\circ} \mathrm{N}, 115.42^{\circ} \mathrm{E}-\right.$ $117.50^{\circ} \mathrm{E}$ ). The blue box in (a) denotes Beijing and is enlarged to the shaded area in (b). The blue triangles in (b) denote four sites in the Beijing-Tianjin-Hebei Atmospheric Environment Monitoring Network.

MADE/SORGAM (Modal Aerosol Dynamics Model for Europe (MADE) and Secondary Organic Aerosol Model (SORGAM)) aerosol model (Ackermann et al., 1998; Schell et al., 2001) and the other one is CBMZ (Carbon Bond Mechanism) photochemical mechanism (Zaveri and Peter, 1999) and MOSAIC (Model for Simulating Aerosol Interactions and Chemistry) aerosol model (Zaveri et al., 2008) which was implemented by Fast et al. (2006). The RADM2 chemistry mechanism with the MADE/SORGAM aerosol model is used in this study. For the treatment of aerosol size distribution, MADE/SORGAM uses the modal approach with three lognormal modes (Aikten, accumulation and coarse mode). All major components of aerosol are treated in the model including $\mathrm{SO}_{4}, \mathrm{NO}_{3}, \mathrm{NH}_{4}, \mathrm{BC}$, $\mathrm{OC}$, sea salt, mineral dust, and aerosol water. Aerosol processes in the MADE/SORGAM include nucleation, condensation of both inorganic and organic aerosol, coagulation, dry/wet deposition, gas phase and aqueous phase chemistry, and water uptake of aerosols. Aerosol nucleation is the most important process for the formation of secondary aerosol particles in the sulfuric acid-water system and is calculated following Kulmala et al. (1998). Aerosol growth by condensation occurs in two steps: the production of condensable material (vapor) by reactions of chemical precursors, and the condensation and evaporation of ambient volatile species on aerosols using the modal approach of Binkowski and Shankar (1995). The formulation for the coagulation process follows Whitby et al. (1991) and Binkowski and Shankar (1995). Dry deposition in MADE/SORGAM is calculated through the deposition velocity which is proportional to the sum of aerodynamic, sublayer, and surface resistances from the parameterization by Wesley (1989). Wet deposition includes the in-cloud aerosol removal based on the conversion rate of cloud water to rain water, and below-cloud aerosol removal by impaction and interception, following the formulation by Easter et al. (2004) for both large-scale and convective precipitation. Aerosol-cloud interactions were included in the model by Gustafson et al. (2007) for calculat- ing the activation and resuspension between dry aerosols and cloud droplets, which is similar to the method used in the MIRAGE general circulation model (Ghan et al., 2001).

\subsection{Numerical experiments}

In this study, WRF-Chem is configured to cover East Asia $\left(10-55^{\circ} \mathrm{N}, 70-150^{\circ} \mathrm{E}\right)$ with $110^{\circ}(\mathrm{S}-\mathrm{N}) \times 160^{\circ}(\mathrm{W}-\mathrm{E})$ grid points, a $36 \mathrm{~km}$ horizontal resolution centering at central China $\left(30^{\circ} \mathrm{N}, 110^{\circ} \mathrm{E}\right)$, and 35 vertical layers up to $10 \mathrm{hPa}$. Figure 1a shows the experiment domain (the outer-most box), and the shaded area in Fig. 1b (enlarged from the blue box in Fig. 1a) shows Beijing (39.43-41.05 $\mathrm{N}, 115.42-$ $\left.117.50^{\circ} \mathrm{E}\right)$. Here, the scope of Beijing includes urban area and rural areas according to administrative divisions. The Runge-Kutta 3rd order time-integration scheme, Noah land surface model, Mellor-Yamada-Janjic Planetary Boundary Layer scheme, and Grell-Devenyi Ensemble Cumulus clouds scheme are used in this study. The land use data used in the model are from 5 min resolution USGS (United States Geological Survey) 24 category data, which were derived from $1 \mathrm{~km}$ Advanced Very High Resolution Radiometer (AVHRR) measurement in a 12-month period spanning from April 1992 to March 1993 (Loveland et al., 1991; Brown et al., 1993). The Lin cloud microphysics scheme is used to include the aerosol indirect effect and RRTMG longwave/shortwave scheme is used to include aerosol direct effect (Zhao et al., 2010a). For chemistry, RADM2 photochemical mechanism, MADE/SORGAM aerosol model and Fast-J Photolysis scheme are used. The initial meteorological fields and boundary conditions are from NCEP Final reanalysis data with $1^{\circ} \times 1^{\circ}$ spatial resolution and $6 \mathrm{~h}$ temporal resolution. The chemical initial and boundary conditions are from the default profiles in WRF-Chem, which are the same as those in the work by McKeen et al. (2002) and are based on averages of mid-latitude aircraft profiles from several field studies over the eastern Pacific Ocean. The initial chemical condition is not going to affect our results, since we have onemonth spin-up for simulations. There are reasons for using default chemical boundary condition rather than the output of global models. The aerosol schemes in global models can be different from that in WRF-Chem. The speciation difference of aerosol species between global models and WRFChem can be large, particularly for the dust aerosol. In addition, global models themselves can have biases in aerosol simulation. On the other hand, although the default chemical boundary condition may affect the chemical condition at the west boundary of domain (e.g. over the Indian region), based on the size of the domain in this study, we would not expect much impact from the west boundary on the air quality in Beijing over East China during the summer (e.g. Zhao et al., 2010b). Therefore, we decided using default chemical boundary profiles instead of obtaining the boundary information from global models in this study. 
The simulation is conducted for the period of May to September 2008 by reinitializing meteorological conditions every 5 days with NCEP Final reanalysis data and including an overlap period of one day for each simulation block for meteorological spin up. The modeled $u$-component and $v$-component of wind, temperature and water vapor mixing ratio are also nudged over the whole domain. The method of nudging (Newtonian relaxation) relaxes the modeled state toward the observed state by adding, to one or more of the prognostic equations, artificial tendency terms based on the difference between modeled and observed states (Stauffer and Seaman, 1990, 1994; Stauffer et al., 1991). The simulation is nudged towards the NCEP reanalysis data with a nudging time scale of $6 \mathrm{~h}$.

We conducted five numerical experiments from 1 May to 2 September 2008 as listed in Table 1: (1) the control experiment (CTL) was driven by the meteorological conditions of 2008 and the emissions of 2008 with emission controls from 20 July to 2 September; (2) experiment (CTL-BJ0) was driven by the meteorological conditions of 2008 and the emissions of 2008 but with emissions in Beijing (Fig. 1b) set to be zero and with emission controls over the rest of model domain from 20 July to 2 September; (3) experiment (CTL-RD0) was driven by the meteorological conditions of 2008 and the emissions of 2008 with emission controls in Beijing and with emissions over the rest of model domain (i.e. domain outside the inner blue box in Fig. 1a) set to be zero from 20 July to 2 September; (4) experiment (NO-CTL) was driven by the meteorological conditions of 2008 and the business-as-usual emissions of 2008 (i.e. no emission controls); (5) experiment (NO-CTL07) was driven by the meteorological conditions of 2007 and the emissions of 2007.

\subsection{Emissions}

Anthropogenic emissions of $\mathrm{CO}, \mathrm{NO}_{\mathrm{x}}, \mathrm{SO}_{2}$, volatile organic compounds (VOCs), $\mathrm{BC}, \mathrm{OC}, \mathrm{PM}_{2.5}$ and $\mathrm{PM}_{10}$ used in the simulations over the model domain are obtained from David Streets' 2006 emission inventory (http://www.cgrer.uiowa. edu/EMISSION_DATA_new/index_16.html), which consists of four sectors (power, industry, residential, and transportation). According to the increase of anthropogenic emissions in Asia from 2001 to 2006 (Q. Zhang et al., 2009), we calculate the increasing rate for each species of anthropogenic emissions per year to be $3.36 \%$ for $\mathrm{CO}, 9.16 \%$ for $\mathrm{NO}_{\mathrm{x}}, 6.34 \%$ for $\mathrm{SO}_{2}, 5.22 \%$ for VOC, $2.66 \%$ for BC, OC and $\mathrm{PM}_{2.5}$, and $2.47 \%$ for $\mathrm{PM}_{10}$, and project the emissions for 2007 and 2008. As there is no $\mathrm{NH}_{3}$ emission in the David Streets' 2006 emission inventory, we use the 2008 $\mathrm{NH}_{3}$ emission from Regional Emission inventory for Asia domain (REAS, http://www.jamstec.go.jp/frsgc/research/d4/ emission.htm). Biomass burning emission is obtained from the Global Fire Emissions Database, Version 2 (GFEDv2.1), which has one-month temporal resolution (Randerson et al., 2005). Biogenic emission is from the Model of Emission of
Gases and Aerosol from Nature (MEGAN) (Guenther et al., 2006). Dust emission is calculated online following Zhao et al. (2011). There is no information available for the vertical distribution of anthropogenic emissions over East Asia, so we emitted the emissions into the lowest model layer. For horizontal distribution, the anthropogenic emissions are interpolated from the raw data grids $(0.5 \times 0.5$ degree $)$ into our domain grids $(36 \times 36 \mathrm{~km})$. As far as we know, the diurnal or daily emission inventory is not available over East Asia. We thus assumed no temporal variation of anthropogenic emissions in this study. Only the temporal change of anthropogenic emissions due to emission control is considered (i.e. different percentage of emission reductions for different periods).

According to the study by S. Wang et al. (2010) for the emission reduction in Beijing during the Olympics, (and personal communication, K. He of Tsinghua University, 2011), we estimate that from 20 July to 7 August prior to the Olympic Games and from 25 August to 6 September after the Olympic Games, anthropogenic emissions decreased by $35 \%$ for Beijing, $20 \%$ for Hebei province (the province immediately surrounding Beijing) and $10 \%$ for other places in China. During the Olympic Games (8-24 August) and Paralympics (7-19 September), anthropogenic emissions decreased by $50 \%$ for Beijing, $35 \%$ for Hebei province and $10 \%$ for other places in China. The restrictions on coal burning pollution in the provinces (Hebei, Shanxi, Inner Mongolia, Shandong, etc.) surrounding Beijing were conducted based on the air quality status in Beijing, which worked together to protect Beijing's air quality. Thus, we estimate that the emission control in Hebei province (the province immediately surrounding Beijing) was weaker than that in Beijing, but stronger than the emission control in other provinces. These estimated emissions are used in our numerical experiments listed in Table 1. We note that there are uncertainties with the actual starting date of emission controls and exact emission reduction percentages in Beijing and surrounding provinces. We will discuss their impact on our conclusions in Sect. 5.

\section{Observational Data}

\subsection{Beijing-Tianjin-Hebei Atmospheric Environment Monitoring Network}

Observations of $\mathrm{PM}_{2.5}$ (Xin et al., 2010) from July to September 2008 were obtained from the Beijing-TianjinHebei Atmospheric Environment Monitoring Network that was supported by the Beijing Olympic Technological Project of the Chinese Academy of Sciences and the Beijing Municipal Environmental Protection Bureau and operated by the Institute of Atmospheric Physics, Chinese Academy of Sciences. The instruments of the network include a Model 42C\&42I $\mathrm{NONO}_{2}-\mathrm{NO}_{\mathrm{x}}$ Analyzer, a Model 43C\&43I 
Table 1. Numerical experiments performed in this study.

\begin{tabular}{ll}
\hline Experiment & Emission used in the WRF-Chem simulation \\
\hline CTL & 2008 emission with emission controls from 20 Jul-2 Sep \\
\hline CTL-BJ0 & $\begin{array}{l}\text { 2008 emission over Beijing is set to zero and with emission control } \\
\text { over the rest of the model domain from 20 Jul-2 Sep }\end{array}$ \\
\hline CTL-RD0 & $\begin{array}{l}\text { 2008 emission with emission control over Beijing and emission over } \\
\text { the rest of model domain is set to zero from 20 Jul-2 Sep }\end{array}$ \\
\hline NO-CTL & 2008 emission without emission control from 20 Jul-2 Sep \\
\hline NO-CTL07 & 2007 emission from May to Sep \\
\hline
\end{tabular}

$\mathrm{SO}_{2}$ Analyzer, a Model 49C\&49I $\mathrm{O}_{3}$ Analyzer, and a Model RP 1400-PM 2.5 . The four sites in the network are $\mathrm{T} 1\left(40.00^{\circ} \mathrm{N}, 116.38^{\circ} \mathrm{E}\right), \mathrm{T} 2\left(40.13^{\circ} \mathrm{N}, 116.13^{\circ} \mathrm{E}\right), \mathrm{T} 3$ $\left(40.42^{\circ} \mathrm{N}, 117.48^{\circ} \mathrm{E}\right)$, and $\mathrm{T} 4\left(39.60^{\circ} \mathrm{N}, 116.75^{\circ} \mathrm{E}\right)$, which are shown in Fig. $1 \mathrm{~b}$ as blue triangles. $\mathrm{T} 1$ is an urban site located between the North Third Ring road and the North Forth Ring road. T2, T3 and T4 are suburban sites, which are more than $35 \mathrm{~km}$ away from Beijing urban area and distributed in different directions of Beijing.

\subsection{Olympic monitoring campaign by China Meteorological Administration (CMA)}

The 2008 Olympic Monitoring Campaign was operated by CMA from June to September 2008 (X.-Y. Zhang et al., 2010). Various atmospheric components including $\mathrm{SO}_{4}$, $\mathrm{NO}_{3}, \mathrm{NH}_{4}$, and $\mathrm{BC}$ were measured at three urban stations and four rural stations in Beijing and its vicinity. The observations at $\mathrm{CMA}\left(39.95^{\circ} \mathrm{N}, 116.33^{\circ} \mathrm{E}\right)$ site, which is located in the urban area of Beijing, are available to us and used in this study.

\subsection{PERSIANN}

We use the PERSIANN hourly precipitation data (Hsu et al., 1999; Sorooshian et al., 2000) during July and August of 2008 on a $0.25^{\circ}$ grid $\left(60^{\circ} \mathrm{S}-60^{\circ} \mathrm{N}\right)$. In the PERSIANN system, a neural network trained by precipitation from the TRMM Microwave Imager (TMI) and other microwave measurements (Hsu et al., 1997, 1999) was used to estimate $30 \mathrm{~min}$ precipitation rates from infrared (IR) and visible imagery from geostationary satellites.

\section{Results}

\subsection{Reduction of aerosol concentrations during the Olympic Games}

Time series of $\mathrm{PM}_{2.5}$ concentration at the surface layer during July and August of 2008 are shown in Fig. 2 to illustrate
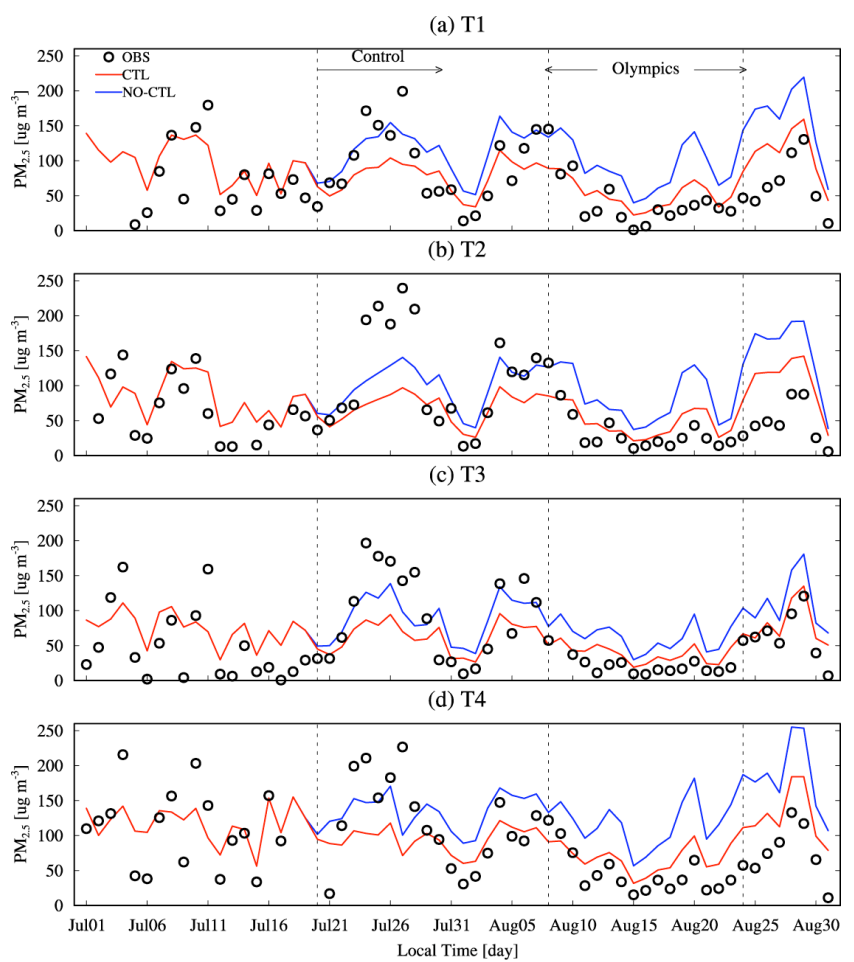

Fig. 2. Daily $\mathrm{PM}_{2.5}$ from observations and the corresponding WRFChem simulations in CTL and NO-CTL cases from 1 July to 31 August at the four sites (T1, T2, T3 and T4).

the change of air quality during the Olympics. This figure compares the observed and simulated $\mathrm{PM}_{2.5}$ concentration in the CTL and NO-CTL cases at four sites (T1, T2, T3, and T4) of the Beijing-Tianjin-Hebei Atmospheric Environment Monitoring Network. These four sites are chosen as they can represent different areas of Beijing (Fig. 1b). In general, model simulation in the CTL case captures the daily variations of observed $\mathrm{PM}_{2.5}$ concentration at the four sites in July and August. For all the sites, there are four $\mathrm{PM}_{2.5}$ concentration peaks on 9 to 11 July, 24 to 26 July, 4 to 9 August, 


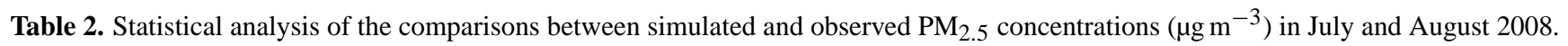

\begin{tabular}{lcccccccccc}
\hline \multirow{2}{*}{ Site name } & \multirow{2}{*}{$\mathrm{N}$} & ${ }^{\mathrm{b}} C_{\text {OBS }}$ & \multicolumn{2}{c}{${ }^{\mathrm{c}} R$} & \multicolumn{2}{c}{${ }^{\mathrm{d}} \mathrm{MB}$} & \multicolumn{2}{c}{${ }^{\mathrm{d}} \mathrm{NMB}(\%)$} & \multicolumn{2}{c}{${ }^{\mathrm{e}} \mathrm{RMSE}$} \\
& & & $\mathrm{CTL}$ & $\mathrm{NO}-\mathrm{CTL}$ & $\mathrm{CTL}$ & $\mathrm{NO}-\mathrm{CTL}$ & $\mathrm{CTL}$ & NO-CTL & CTL & NO-CTL \\
\hline $\mathrm{T} 1$ & 58 & 69.3 & 0.65 & 0.62 & 9.8 & 38.9 & 14.2 & 56.2 & 38.1 & 55.6 \\
$\mathrm{~T} 2$ & 59 & 69.4 & 0.51 & 0.50 & 3.3 & 28.3 & 4.8 & 40.8 & 50.2 & 58.6 \\
$\mathrm{~T} 3$ & 61 & 57.5 & 0.61 & 0.70 & 5.1 & 23.0 & 8.8 & 40.0 & 42.8 & 44.8 \\
$\mathrm{~T} 4$ & 59 & 90.3 & 0.59 & 0.39 & 7.2 & 40.4 & 8.0 & 44.8 & 46.6 & 68.3 \\
\hline
\end{tabular}

${ }^{\text {a }} N$ is the number of daily samples between observations and model results in July and August.

${ }^{\mathrm{b}} C_{\mathrm{OBS}}$ is the daily value of observations averaged in July and August.

${ }^{\mathrm{c}} R$ is the correlation coefficient between observations and model results of CTL and NO-CTL, respectively.

$\mathrm{d}$ MB is the mean bias between model results of CTL and NO-CTL and observations, respectively. NMB is the normalized mean bias between model results of CTL and NO-CTL and observations, respectively.

${ }^{\mathrm{e}} \mathrm{RMSE}$ is the root mean square error between model results of CTL and NO-CTL and observations, respectively.

and 28 August. Observed $\mathrm{PM}_{2.5}$ concentrations at $\mathrm{T} 1$ site are $120-180 \mu \mathrm{g} \mathrm{m}^{-3}$ at these peaks. During other periods, $\mathrm{PM}_{2.5}$ concentrations are much lower, especially for the Olympic period with values of $40-70 \mu \mathrm{g} \mathrm{m}^{-3}$. Both simulations and observations show that $\mathrm{PM}_{2.5}$ concentrations at $\mathrm{T} 2$ site have almost the same fluctuations as those at $\mathrm{T} 1$ site and also have the similar values of $\mathrm{PM}_{2.5}$ concentrations, although $\mathrm{T} 2$ is a suburban site. Both observed and simulated $\mathrm{PM}_{2.5}$ concentrations at $\mathrm{T} 3$ site are the lowest during the Olympic period compared to other sites as it is located in the northeast direction of Beijing, which is a mountain area with relatively clean background. Observed and simulated $\mathrm{PM}_{2.5}$ concentrations at $\mathrm{T} 4$ site are similar to or often higher than those at the urban site (T1) because T4 site is surrounded by several other industrial cities such as Tianjin and Tangshan. At all the four sites, $\mathrm{PM}_{2.5}$ concentrations are significantly underestimated by the model during 24-28 July while overestimated during 24-30 August. The underestimation might be due to the incorrect emissions. The overestimation is associated with the bias in simulated grid-scale precipitation, which will be discussed in Sect. 4.2.2. Modeled PM$_{2.5}$ concentrations from the CTL case agree with observations reasonably well during the Olympic period, although the model results slightly overestimate the observations. In comparison modeled $\mathrm{PM}_{2.5}$ concentrations from the NO-CTL case significantly overestimate the observations. The comparison between the CTL and NO-CTL case will be discussed in Sect. 4.2.1 to illustrate the impact of emission controls.

Table 2 summarizes the statistical analysis between observed and simulated daily $\mathrm{PM}_{2.5}$ concentrations in both CTL and NO-CTL cases at the four sites (in Fig. 2) from July to August 2008. $N$ is the number of daily samples between observations and simulations at each site in July and August. The correlation coefficients $(R)$ between observations and model simulations in both cases range from 0.5 to 0.7. The similar $R$ values for both cases indicate that emission controls have a limited impact on the co-variation of modeled and observed $\mathrm{PM}_{2.5}$ concentrations. There is pos- itive mean bias (MB) of $\mathrm{PM}_{2.5}$ concentration from the CTL case compared to observations with values of 9.8, 3.3, 5.0, and $7.2 \mu \mathrm{g} \mathrm{m}^{-3}$ for the four sites, respectively, which are, however, substantially lower than the values of 38.9, 28.3, 23.0, and $40.4 \mu \mathrm{g} \mathrm{m}^{-3}$ from the NO-CTL case. In addition, the normalized mean bias (NMB) ranges from $4.8 \%$ to $14.2 \%$ in the CTL case, which is much lower than the corresponding NMB of $40.0 \%$ to $56.0 \%$ in the NO-CTL case for the four sites. The root mean square error (RMSE) is also reduced in the CTL case. The improvement of model simulation in the CTL case compared to the NO-CTL case indicates that emission controls effectively reduce the aerosol particle concentrations.

Table 3 shows the $\mathrm{PM}_{2.5}$ concentrations at the above sites from observations and simulations in the CTL, NOCTL and NO-CTL07 cases averaged for the four sub-periods from July to August (i.e. prior to emission controls: 1-19 July; with emission controls prior to Olympic Games: 20 July-7 August; with emission controls during the Olympic Games: 8-24 August; and with emission controls postOlympic Games: 25-31 August). At T1 site, the observed $\mathrm{PM}_{2.5}$ concentration is $42.4 \mu \mathrm{g} \mathrm{m}^{-3}$ during the Olympic period, lower than the values of $68.2-92.4 \mu \mathrm{g} \mathrm{m}^{-3}(40-50 \%$ lower) during the other periods from July to August 2008. The CTL case also simulates the lowest $\mathrm{PM}_{2.5}$ concentration of $54.5 \mu \mathrm{g} \mathrm{m}^{-3}$ during the Olympic period, compared to the values of $78.0-112.2 \mu \mathrm{g} \mathrm{m}^{-3}$ (30-50\% lower) during the other periods from June to August 2008. At T2 site, the observed $\mathrm{PM}_{2.5}$ concentration is $35.3 \mu \mathrm{g} \mathrm{m}^{-3}$ during the Olympic period, which is lower than the values of $48.7-109.6 \mu \mathrm{g} \mathrm{m}^{-3}$ (30-70\% lower) during the other periods from July to August 2008. $\mathrm{PM}_{2.5}$ concentration from the

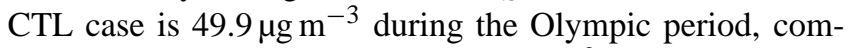
pared to the values of $68.8-107.3 \mu \mathrm{g} \mathrm{m}^{-3}$ (30-50\% lower) during the other periods from July to August 2008. At T3 site, the observed $\mathrm{PM}_{2.5}$ concentration is $23.5 \mu \mathrm{g} \mathrm{m}^{-3}$ during the Olympic period, which is $50-75 \%$ lower than the values of $48.5-92.6 \mu \mathrm{g} \mathrm{m}^{-3}$ during the other periods. The CTL 
Table 3. Comparisons of observed and modeled averaged $\mathrm{PM}_{2.5}$ concentrations $\left(\mu \mathrm{g} \mathrm{m}^{-3}\right.$ ) during four sub-periods at four sites. The column with numbers in bold denotes the $\mathrm{PM}_{2.5}$ concentration during Beijing Olympic Games (8-24 August).

\begin{tabular}{rlrrrr}
\hline Site name & & 1-19 Jul & 20 Jul-7 Aug & 8-24 Aug & 25-31 Aug \\
& & 70.9 & 92.4 & $\mathbf{4 2 . 4}$ & 68.2 \\
T1 & OBS & 92.8 & 78.0 & $\mathbf{5 4 . 5}$ & 112.2 \\
& CTL & 92.8 & 112.9 & $\mathbf{9 5 . 2}$ & 159.7 \\
& NO-CTL & 104.1 & $\mathbf{7 3 . 7}$ & 56.4 \\
\hline \multirow{4}{*}{ NO-CTL07 } & 90.1 & 109.6 & $\mathbf{3 5 . 3}$ & 48.7 \\
& OBS & 66.7 & 68.8 & $\mathbf{4 9 . 9}$ & 107.3 \\
& CTL & 86.2 & 99.0 & $\mathbf{8 5 . 5}$ & 149.6 \\
& NO-CTL & 86.2 & 94.3 & $\mathbf{5 8 . 6}$ & 46.8 \\
\hline \multirow{4}{*}{ T3 } & NO-CTL07 & 80.2 & 92.6 & $\mathbf{2 3 . 5}$ & 64.2 \\
& OBS & 48.5 & 63.2 & $\mathbf{3 8 . 9}$ & 81.6 \\
& CTL & 74.7 & 89.6 & $\mathbf{6 3 . 0}$ & 111.6 \\
& NO-CTL & 74.7 & 84.1 & $\mathbf{6 5 . 0}$ & 49.3 \\
\hline \multirow{3}{*}{ T4 } & NO-CTL07 & 74.7 & 117.5 & $\mathbf{4 7 . 2}$ & 77.8 \\
& OBS & 109.8 & 94.6 & $\mathbf{7 0 . 2}$ & 129.1 \\
& CTL & 114.8 & 135.2 & $\mathbf{1 2 0 . 4}$ & 183.6 \\
& NO-CTL & 114.8 & 124.0 & $\mathbf{1 0 7 . 9}$ & 81.8 \\
\hline
\end{tabular}

case simulated $\mathrm{PM}_{2.5}$ concentration is $38.9 \mu \mathrm{g} \mathrm{m}^{-3}$, which is $35-50 \%$ lower than the values of $63.2-81.6 \mu \mathrm{g} \mathrm{m}^{-3}$ during the other periods. At $\mathrm{T} 4$ site, the observed $\mathrm{PM}_{2.5}$ concentration is $47.2 \mu \mathrm{g} \mathrm{m}^{-3}$ during the Olympic period, which is $40-60 \%$ lower than the values of $77.8-117.5 \mu \mathrm{g} \mathrm{m}^{-3}$ during the other periods. Simulated $\mathrm{PM}_{2.5}$ concentration in the CTL case is $70.2 \mu \mathrm{g} \mathrm{m}^{-3}$ during the Olympic period, which is $25-$ $50 \%$ lower than the values of $94.6-129.1 \mu \mathrm{g} \mathrm{m}^{-3}$ during the other periods. From the above discussion, modeled $\mathrm{PM}_{2.5}$ concentration from the CTL case during the Olympic period is $25-50 \%$ lower than the values during the other periods. Observations show even larger reductions (by up to $75 \%$ ). This is because the model simulation (CTL) underestimates $\mathrm{PM}_{2.5}$ concentration during 20 July-7 August (Fig. 2). Thus the modeled difference between this period and the Olympics period is underestimated. Some measurement studies (e.g. Y. Wang et al., 2009) reported the effectiveness of emission controls by comparing aerosol and/or precursor concentrations during the Olympic period with those of the same period in 2006 and 2007 (same as our NO-CTL07 case). We note that the conclusion drawn from such comparisons may not be robust since there are strong inter-annual variations of meteorological conditions. As shown in Table 3, $\mathrm{PM}_{2.5}$ concentrations are significantly different between the NO-CTL case during the Olympic period and the NO-CTL07 case during the same period at T1, T2 and T4 sites. Without emission control, we would not expect much difference between the emissions in 2007 and 2008. Thus aerosol concentration differences between NO-CTL and NO-CTL07 are mainly due to the difference in meteorological conditions between 2007 and 2008 .
Table 4 lists the aerosol concentrations of $\mathrm{SO}_{4}, \mathrm{NH}_{3}, \mathrm{NH}_{4}$, $\mathrm{BC}$, and $\mathrm{OC}$ from observations at the CMA site $\left(39.95^{\circ} \mathrm{N}\right.$, $\left.116.33^{\circ} \mathrm{E}\right)(\mathrm{X} .-\mathrm{Y}$. Zhang et al., 2010) and model simulations in the CTL and NO-CTL cases averaged for the five subperiods from 1 June to 31 August 2008. In general, the model underestimates observed $\mathrm{SO}_{4}$, which may be caused by the underestimation of $\mathrm{SO}_{2}$ emission in the model. Both observations and model simulations in the CTL case show that the aerosol species concentrations are much lower during the Olympic period (8-24 August) than those during the pre- and post-Olympic periods. The observed $\mathrm{SO}_{4}$ concentration is $12.0 \mathrm{\mu g} \mathrm{m}^{-3}$ during the Olympic period, lower than the values of $19.9-25.2 \mu \mathrm{g} \mathrm{m}^{-3}$ (35-50\% lower) during the other periods from June to August 2008. The CTL case also simulates the lowest $\mathrm{SO}_{4}$ concentration of $9.4 \mu \mathrm{g} \mathrm{m}^{-3}$ during the Olympic period, compared to the values of $15.2-$ $18.6 \mu \mathrm{g} \mathrm{m}^{-3}$ (40-60\% lower) during the other periods from June to August 2008. For $\mathrm{NO}_{3}$, model results are higher than observations, reflecting the difficulty of model to simulate the partitioning of $\mathrm{HNO}_{3}(\mathrm{~g})$ into aerosol phase. The observed $\mathrm{NO}_{3}$ concentration is $7.0 \mu \mathrm{g} \mathrm{m}^{-3}$ during the Olympic period, which is also 30-60\% lower than the values of 11.4$20.4 \mu \mathrm{g} \mathrm{m}^{-3}$ during the other periods from July to August 2008. In the CTL case, $\mathrm{NO}_{3}$ concentration is also the lowest with the value of $15.5 \mathrm{\mu g} \mathrm{m}^{-3}$ during Olympic period, comparing to $21.6-40.8 \mu \mathrm{g} \mathrm{m}^{-3}$ (30-60\% lower) during other periods from June to August 2008. The observed $\mathrm{NH}_{4}$ concentration is $6.6 \mu \mathrm{g} \mathrm{m}^{-3}$ during the Olympic period, which is $30-50 \%$ lower than the values of $9.4-12.7 \mu \mathrm{g} \mathrm{m}^{-3}$ during the other periods from June to August 2008. In the CTL case, there is the lowest $\mathrm{NH}_{4}$ concentration of $8.0 \mu \mathrm{g} \mathrm{m}^{-3}$ 
during the Olympic period, compared to the values of 12.1$18.8 \mathrm{\mu g} \mathrm{m}^{-3}$ (30-50\% lower) during the other periods from June to August 2008. The model simulated BC concentrations for the CTL case agree well with observations. The observed $\mathrm{BC}$ concentration is $3.0 \mu \mathrm{g} \mathrm{m}^{-3}$ during the Olympic period, lower than the values of $4.8-6.5 \mu \mathrm{g} \mathrm{m}^{-3}$ (35-50\% lower) during other periods from June to August 2008. The CTL case also simulates the lowest BC concentration of $3.8 \mu \mathrm{g} \mathrm{m}^{-3}$ during the Olympic period, compared to the values of 5.6-7.3 $\mu \mathrm{g} \mathrm{m}^{-3}$ (35-50\% lower) during the other periods from June to August 2008. For OC, model significantly underestimates observations because of the incomplete treatment of secondary organic aerosol (SOA) in the WRF-Chem model (e.g. Li et al., 2010; Shrivastava et al., 2010). OC concentrations from both model simulations for the CTL case and observations during the Olympics are about $60 \%$ of those prior to the Olympics. As discussed above, both observations and model results show that the concentrations of all the aerosol species are about $35 \%-50 \%$ lower during the Olympic period than those in the other periods from June to August 2008.

\subsection{Factors for aerosol concentration reduction during the Olympic Games}

\subsubsection{Emission controls}

Both observations and model simulations show that aerosol concentrations decreased significantly during the Olympic period compared to the values during the other periods of June-August 2008. In the following, we will investigate the relative roles of emission controls and meteorological conditions in affecting this reduction. Comparing model results between CTL and NO-CTL, emission controls significantly reduce $\mathrm{PM}_{2.5}$ and aerosol species concentrations during the Olympic period (Fig. 2, Table 3 and Table 4). PM 2.5 concentration is reduced by $\sim 40 \%$ for all the four sites (Fig. 2 and Table 3), while the concentration of $\mathrm{SO}_{4}, \mathrm{NO}_{3}, \mathrm{NH}_{4}, \mathrm{BC}$, and OC is reduced by $26 \%, 53 \%, 44 \%, 46 \%$, and $44 \%$, respectively at the CMA site (Table 4). Figure 3 shows the spatial distribution of the concentration difference of $\mathrm{SO}_{4}$, $\mathrm{NO}_{3}, \mathrm{NH}_{4}, \mathrm{BC}, \mathrm{OC}$, and $\mathrm{PM}_{2.5}$ between the CTL case and the NO-CTL case averaged from 20 July to 31 August (i.e. including both the Olympic period and pre-Olympic period but with full-scale emission controls) over Beijing. The reduction of $\mathrm{SO}_{4}$ is about $2-3 \mu \mathrm{g} \mathrm{m}^{-3}$ over north of Beijing and $3-4 \mu \mathrm{g} \mathrm{m}^{-3}$ over south of Beijing and the relative reduction is $\sim 20 \%$ over Beijing. The reduction of $\mathrm{NO}_{3}$ is the most among all the species, which is about $6-12 \mu \mathrm{g} \mathrm{m}^{-3}$ over north of Beijing and $12-18 \mu \mathrm{g} \mathrm{m}^{-3}$ over south of Beijing. The relative reduction of $\mathrm{NO}_{3}$ is $\sim 40 \%$ over Beijing. Reduction of $\mathrm{NH}_{4}$ is about $3-4 \mu \mathrm{g} \mathrm{m}^{-3}$ over north of Beijing and $4-6 \mu \mathrm{g} \mathrm{m}^{-3}$ over south of Beijing, and the relative reduction is $30-35 \%$ over Beijing. The reduction of $\mathrm{BC}$ is about $1-3 \mu \mathrm{g} \mathrm{m}^{-3}$ over Beijing, and the reduction of OC is about

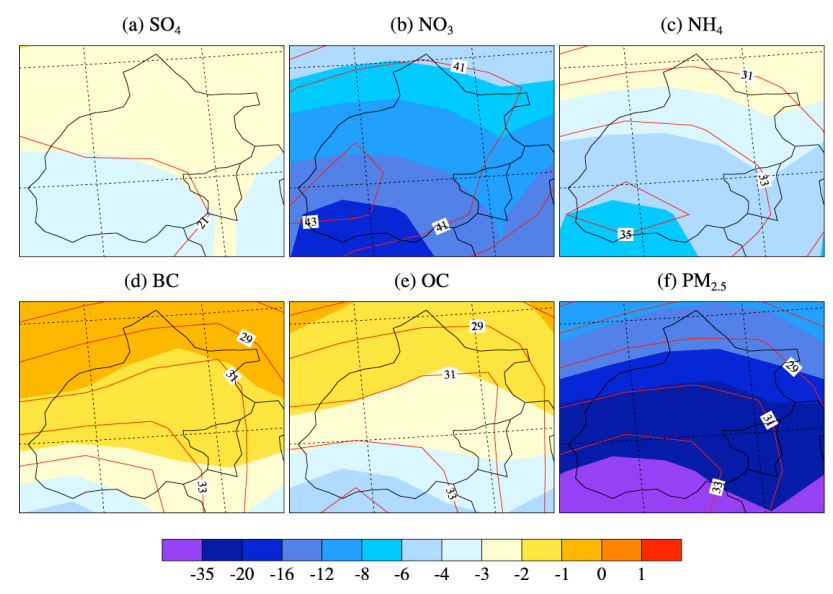

Fig. 3. Spatial distribution of the difference of time-averaged concentration between CTL case and NO-CTL case for (a) $\mathrm{SO}_{4}$, (b) $\mathrm{NO}_{3}$, (c) $\mathrm{NH}_{4}$, (d) $\mathrm{BC}$, (e) $\mathrm{OC}$, and (f) $\mathrm{PM}_{2.5}$ from 20 July to 31 August over Beijing. The color fill is the absolute difference in $\mu \mathrm{g} \mathrm{m}^{-3}$ and the red solid contour lines with number are the relative differences in percentage $(\%)$.

$1-4 \mu \mathrm{g} \mathrm{m}^{-3}$ over Beijing. The relative reduction of $\mathrm{BC}$ and $\mathrm{OC}$ are $\sim 30 \%$. For $\mathrm{PM}_{2.5}$, the reduction is $16-20 \mu \mathrm{g} \mathrm{m} \mathrm{m}^{-3}$ over north of Beijing and $20-40 \mu \mathrm{g} \mathrm{m}^{-3}$ over south of Beijing. The relative reduction of $\mathrm{PM}_{2.5}$ is about $30 \%$ over Beijing.

Generally, the emission control is efficient for the reduction of concentrations of all the aerosol species, including $\mathrm{SO}_{4}(20 \%), \mathrm{NO}_{3}(40 \%), \mathrm{NH}_{4}(30 \%), \mathrm{BC}(30 \%)$ and $\mathrm{OC}$ (30\%) during the period from 20 July to 31 August. The reduction in $\mathrm{NO}_{3}$ concentration is most sensitive while the reduction in $\mathrm{SO}_{4}$ concentration is the least for the same scale of emission reductions of all the anthropogenic pollutants. In addition, the reduction in aerosol concentrations from emission controls over south of Beijing is larger than that over north of Beijing as south of Beijing is the urban area and the concentrations of aerosol pollution are higher there. It is noted that although the WRF-Chem simulated $\mathrm{PM}_{2.5}$ concentration is higher than observation during the Olympic and post-Olympic period (Table 3 and Fig. 2), this study focuses more on the relative impact of the emission controls versus meteorological conditions during the Olympic Games. The uncertainty of emissions can affect the absolute values of aerosol concentrations, but not the relative changes, since we apply the percentage reduction of emissions in the CTL case to the NO-CTL case.

\subsubsection{Meteorological conditions}

Although the model simulation with emission controls (the CTL case) shows that the aerosol concentrations in Beijing are significantly reduced during the Olympic Games compared to other periods in July and August and also lower 
Table 4. Comparisons of observed and modeled averaged concentrations $\left(\mu \mathrm{g} \mathrm{m}^{-3}\right)$ of aerosol species during five sub-periods at CMA $\left(39.95^{\circ} \mathrm{N}, 116.33^{\circ} \mathrm{E}\right)$ site (observations from X.-Y. Zhang et al., 2010). The column with numbers in bold denotes the PM 2.5 concentration during Beijing Olympic Games (8-24 August).

\begin{tabular}{llrrrrr}
\hline Species & & June & $1-19$ Jul & 20 Jul-7 Aug & $8-24$ Aug & $25-31$ Aug \\
\hline \multirow{2}{*}{$\mathrm{SO}_{4}$} & OBS & 25.2 & 19.9 & 24.0 & $\mathbf{1 2 . 0}$ & \\
& CTL & 16.4 & 17.4 & 15.2 & $\mathbf{9 . 4}$ & 18.6 \\
& NO-CTL & 16.4 & 17.4 & 19.0 & $\mathbf{1 2 . 7}$ & 23.2 \\
\hline \multirow{3}{*}{$\mathrm{NO}_{3}$} & OBS & 20.4 & 12.4 & 11.4 & $\mathbf{7 . 0}$ & \\
& CTL & 21.6 & 27.3 & 22.1 & $\mathbf{1 5 . 5}$ & 40.8 \\
& NO-CTL & 21.6 & 27.3 & 36.8 & $\mathbf{3 3 . 1}$ & 64.3 \\
$\mathrm{NH}_{4}$ & OBS & 12.7 & 9.4 & 11.6 & $\mathbf{6 . 6}$ & \\
& CTL & 12.4 & 14.4 & 12.1 & $\mathbf{8 . 0}$ & 18.8 \\
& NO-CTL & 12.4 & 14.4 & 17.8 & $\mathbf{1 4 . 4}$ & 27.4 \\
$\mathrm{BC}^{*}$ & OBS & 6.5 & 5.0 & 4.8 & $\mathbf{3 . 0}$ & \\
& CTL & 6.8 & 7.3 & 5.9 & $\mathbf{3 . 8}$ & 5.6 \\
& NO-CTL & 6.8 & 7.3 & 8.5 & $\mathbf{7 . 0}$ & 8.4 \\
\hline \multirow{2}{*}{ OC } & OBS & 33.6 & 24.2 & 20.7 & $\mathbf{1 4 . 8}$ & \\
& CTL & 10.6 & 11.0 & 8.9 & $\mathbf{5 . 8}$ & 8.9 \\
& NO-CTL & 10.6 & 11.0 & 12.6 & $\mathbf{1 0 . 3}$ & 13.0 \\
\hline
\end{tabular}
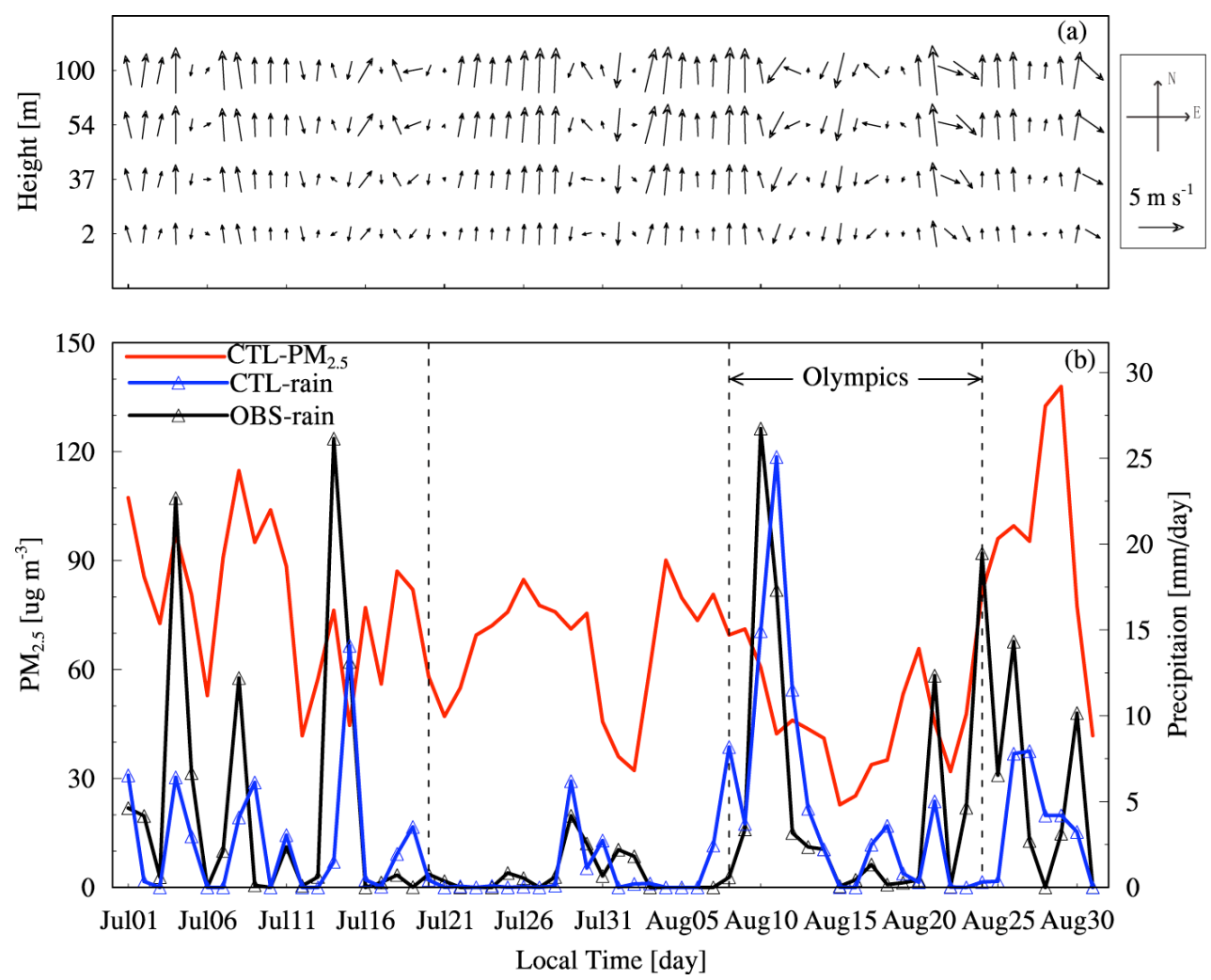

Fig. 4. Time series of (a) daily mean and grid averaged horizontal wind speed and direction from CTL case at the lowest three layers over Beijing and (b) daily mean and grid averaged $\mathrm{PM}_{2.5}$ concentration, daily sum and grid averaged precipitation rate from CTL case and observation over Beijing from 1 July to 31 August. Direction of arrows in (a) denotes the direction of horizontal wind and the length of arrows denotes wind speed. 
than those from the simulation without emission controls (the NO-CTL case) (Fig. 3), we argue that meteorological conditions play a key role in producing the low aerosol concentrations in most of the Olympic period. It is shown that aerosol concentrations from the NO-CTL case during the Olympic period are lower than those from 24 to 26 July, 4 to $7 \mathrm{Au}-$ gust, and 28 August (peaks in Fig. 2). In addition, daily variations of aerosol concentration are large with very high $\mathrm{PM}_{2.5}$ concentrations up to $150 \mu \mathrm{g} \mathrm{m}^{-3}$ in the first two days of Olympics (8-9 August) and in the period of 24 to 26 July when the full-scale emission controls are already enforced. We further suggest that emission controls have a small impact on the daily variations of aerosol concentration during the Olympic period, which, instead, results from the meteorological impact, as will be discussed below.

Figure 4 shows daily averaged horizontal wind speed and direction at the lowest three layers, daily averaged surface $\mathrm{PM}_{2.5}$ concentration from the CTL case, and daily precipitation rate over Beijing from 1 July to 31 August 2008. The direction of arrows in Fig. 4a denotes the horizontal wind direction on the three vertical planes and the length of the arrows denotes the horizontal wind speed. The observed $0.25^{\circ} \times 0.25^{\circ}$ precipitation data is from PERSIANN hourly precipitation data, shown in Fig. 4b. The model generally captures the observed precipitation events in July and August 2008. $\mathrm{PM}_{2.5}$ concentrations are reduced during and immediate after precipitation events (e.g. 29-31 July, 9-11 August) due to the scavenging of aerosols by precipitation. The large fluctuations of $\mathrm{PM}_{2.5}$ concentration during 1-19 July are caused by the frequent occurrence of precipitation events. The few amounts of precipitation around 26 July and 4-8 August contribute to the high $\mathrm{PM}_{2.5}$ concentration during these periods while the heavy precipitation during 9-11 August decreases the $\mathrm{PM}_{2.5}$ concentration during the Olympics. The model underestimation of observed precipitation after 22 August results in the overestimation of $\mathrm{PM}_{2.5}$ concentration during that period (Fig. 2)

The change of $\mathrm{PM}_{2.5}$ concentrations is also related to the variation of wind direction, which, together with the occurrence of precipitation, is associated with the weather patterns in Beijing. As shown in Fig. 4, high $\mathrm{PM}_{2.5}$ concentrations always correspond to the southeasterly, southerly, or southwesterly wind, while low $\mathrm{PM}_{2.5}$ concentrations always correspond to the reverse wind direction (e.g. northeasterly wind). Beijing is surrounded by Yanshan Mountain to the northeast, Taihang Mountain to the west, and Mongolian plateau to the northwest, thus northerly wind blow clean air into Beijing, whereas aerosol particles can be transported by the southerly wind from the southern polluted regions and accumulated over the Beijing area. Figure 4 shows that the dominated southerly wind during 22-26 July and during 4-9 August leads to high $\mathrm{PM}_{2.5}$ concentrations during these periods, while the northeasterly wind during 11-20 August results in a continuous period with low aerosol concentrations for the Olympic Games.
Two sensitivity simulations (CTL-BJ0 and CTL-RD0) are conducted to investigate the relative impact of emissions of Beijing and its surrounding regions on the air quality in Beijing. Figure 5 shows the daily mean and grid averaged anomalies of surface $\mathrm{PM}_{2.5}$ concentration from 20 July to 31 August (the emission control period prior to and during the Olympics) over Beijing from model simulations in the CTL, CTL-BJ0, and CTL-RD0 cases. Anomaly is calculated by subtracting the mean $\mathrm{PM}_{2.5}$ concentration during 20 July-31 August from its daily values. Figure 5 shows that in the CTL-RD0 case with emissions in the regions outside Beijing turned off, fluctuations of $\mathrm{PM}_{2.5}$ concentration become much smaller compared to those in the CTL and CTL-BJ0 cases. In comparison, $\mathrm{PM}_{2.5}$ concentration from CTL and CTL-BJ0 cases has strong correlation (correlation coefficients are 0.98), indicating that pollutants transported from the regions surrounding Beijing dominate the fluctuations of $\mathrm{PM}_{2.5}$ concentration in Beijing. The anomalies of CTL and CTL-BJ0 are almost the same with large positive value around 26 July and 4 August indicating that the transport from regions outside of Beijing is the main cause for the high $\mathrm{PM}_{2.5}$ concentration during these periods. The anomalies of $\mathrm{PM}_{2.5}$ concentrations in the CTL-RD0 case with all emissions outside Beijing turned off (the green line) change from positive to negative on 8 August, indicating the effect of enhanced emission controls in Beijing during the Olympics. From 8 to 24 August, the averaged anomalies in the CTL-BJ0 case are about $-10.6 \mu \mathrm{g} \mathrm{m}^{-3}$, while the averaged anomalies in the CTL-RD0 case are about $-3.1 \mu \mathrm{g} \mathrm{m}^{-3}$. This indicates that the transport of pollutants from regions outside Beijing has a larger impact on the daily variations of aerosol concentration than the emission controls in Beijing during the Olympic period. The above results suggest that meteorological conditions determine the daily fluctuations of aerosol concentration, although emission controls reduce the averaged aerosol concentrations by $30-50 \%$ during the Olympic period.

We note that the well-simulated meteorological condition is the pre-requisite for the robust model results. As discussed in Sect. 2, our model simulations are conducted by reinitializing meteorological conditions every 5 days with NCEP Final reanalysis data and also nudging modeled $u$-component and $v$-component of wind, temperature, and water vapor mixing ratio with NCEP reanalysis data with a nudging time scale of $6 \mathrm{~h}$. Thus model simulated wind, temperature and water vapor mixing ratio are similar to the NCEP reanalysis data. Moreover, we evaluated model simulated hourly wind speed, wind direction, temperature, and relative humidity with observations obtained at the $325 \mathrm{~m}$ Beijing Meteorological Tower for August 2008. In general the model captures the diurnal variations of observed meteorological variables reasonably well except that the model shows frequently higher wind speed and larger diurnal variations of wind speed (see Fig. S1 in the Supplement). The comparison of simulated wind speed and direction with NCEP 


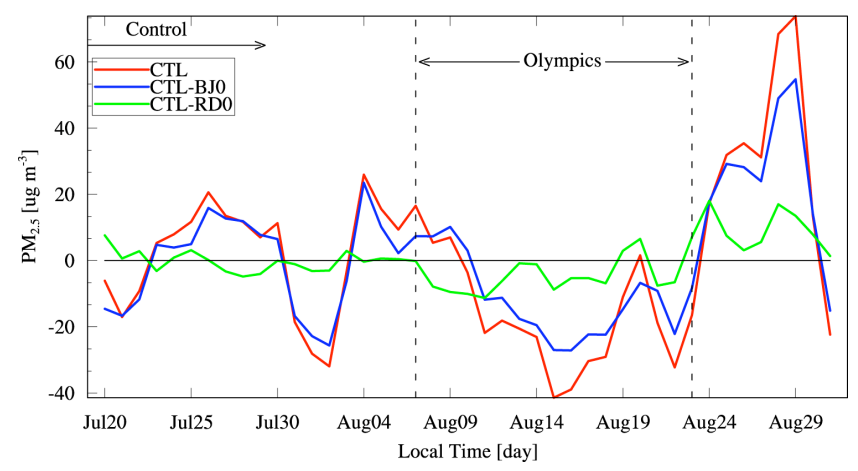

Fig. 5. Time series of the anomaly of daily $\mathrm{PM}_{2.5}$ surface concentration in CTL, CTL-BJ0 and CTL-RD0 case from 20 July to 31 August. Anomaly is calculated by subtracting the averaged surface $\mathrm{PM}_{2.5}$ concentration during 20 July-31 August from its daily values.

Final reanalysis data at the lowest three layers over Beijing is shown in Fig. S2 of the Supplement. The same comparison as Fig. S2 but with a WRF simulation at a higher horizontal resolution $(4 \mathrm{~km})$ with cumulus parameterization turned off is shown in Fig. S3 of the Supplement. The variation of wind speed and direction from the CTL case is similar to that from the $4 \mathrm{~km}$ simulation. Therefore, the relatively coarser resolution $(36 \mathrm{~km})$ in the CTL case is not going to affect our result in terms of the pollution transport surrounding Beijing. It's noteworthy that $4 \mathrm{~km}$ simulation of precipitation rate becomes worse, reflecting the precipitation bias from the microphysics scheme (i.e. Lin scheme used in this study). The investigation of the sensitivity of precipitation rate to different microphysics schemes is beyond the scope of this paper.

We further compare model simulated hourly wind speed, wind direction, temperature, relative humidity, and daily precipitation from both the CTL case and $4 \mathrm{~km}$ WRF simulation with observations at seven other sites in Beijing for July and August 2008. Generally, model reproduces the temporal variation of observations at different sites (see Fig. S5 in the Supplement). Wind speed from the $4 \mathrm{~km}$ WRF simulation agrees better with observations than that from the CTL case by producing lower wind speed. The temporal variation of wind direction is also smaller in $4 \mathrm{~km}$ simulation. However, temperature from the $4 \mathrm{~km}$ simulation is systematically higher (especially at daytime) than that from the CTL case and observations, along with its lower relative humidity. For precipitation, both CTL case and $4 \mathrm{~km}$ simulation can capture the main precipitation events at each site in July and August, but underestimate observed precipitation especially for $4 \mathrm{~km}$ simulation.

\subsubsection{Budget analysis}

In order to further understand the source of variations of aerosol concentrations during the Olympic period, the bud- gets of $\mathrm{BC}$ from emission, chemistry, transport, and dry and wet deposition are calculated for the CTL case. BC is chosen since it has no chemical production/loss in the model, which makes it simple for the analysis of the relative contribution from the transport and emission. Figure 6 shows the July-August budgets for $\mathrm{BC}$ and budget differences between the periods of 2-10 August and 11-19 August and the period of July-August. The positive value denotes increase to concentration and the negative value denotes decrease to concentration over Beijing. " $\Delta$-concentration" equals to the net contributions of the five budget terms. Among the five budget terms (Fig. 6a), emission contribution is always positive, contribution from wet and dry deposition are always negative and transport contribution depends on meteorological conditions. In Fig. 6a, for the budgets in the whole July-August period, the source term of $\mathrm{BC}$ is emission and the loss terms of $\mathrm{BC}$ are transport and dry and wet deposition. $\Delta$-concentration is -4.2 ton day ${ }^{-1}$. Emission has the contribution of 64.5 ton day ${ }^{-1}$. The contribution of transport is -27.9 ton day $^{-1}$ indicating that in July and August 2008, meteorological conditions are favorable for the decrease of air pollutants. The dry deposition loss is -30.7 ton day $^{-1}$ and wet deposition loss is -10.3 ton $\mathrm{day}^{-1}$ for BC.

In Fig. 6b, comparing with the BC budgets in July-August 2008 , for the period of 2 to 10 August (red bars), the negative contribution of transport to BC concentration in Fig. 6a is reduced by 27.1 ton day ${ }^{-1}$ and the positive contribution of emission is reduced by 9.8 ton day $^{-1}$ indicating the unfavorable meteorological conditions and effectiveness of emission controls in this period. The negative contribution of dry deposition is slightly increased by 1.2 ton day ${ }^{-1}$ (more negative) and the negative contribution of wet deposition slightly reduced by 1.9 ton day $^{-1}$ (less negative) indicating the contributions of these two terms in this period are similar to the average conditions in July and August. Therefore, the transport that is not favorable for ventilating the air pollutants during 2-10 August makes BC concentration increase by 17.9 ton day $^{-1}$. For the period of 11-19 August (green bars), the positive contribution of emission in Fig. 6a is reduced by 19.2 ton day $^{-1}$ indicating the enhanced emission controls during this period. The negative contribution of transport is only reduced by a very small amount (about 1.0 ton day ${ }^{-1}$, thus the transport loss is 26.9 ton day $^{-1}$ for this period) indicating that meteorological conditions in this period are as favorable as the average conditions in July and August to ventilate the air pollutants in Beijing. As dry deposition is proportional to the concentrations and the $\mathrm{BC}$ concentration decrease significantly in this period, the negative contribution of dry deposition in Fig. 6a is reduced by 15.1 ton day $^{-1}$. The change of negative contribution of wet deposition is also very small at about 2.2 ton day ${ }^{-1}$. Therefore, during 11-19 August, under favorable meteorological conditions (26.9 ton day $^{-1}$ for transport loss), large decrease in emission (19.2 ton day ${ }^{-1}$ ) is effective for the improvement of air quality during the Olympic Game. Considering that 
(a) Budget

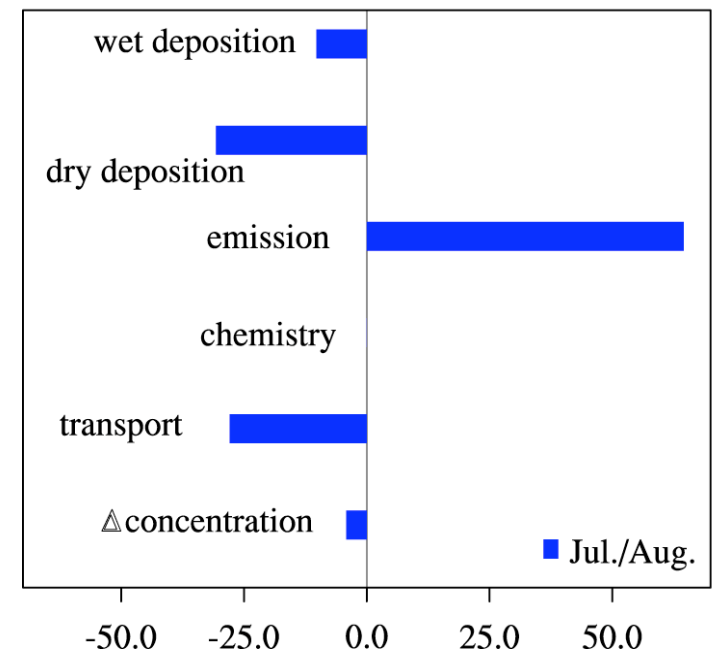

(b) Budget difference

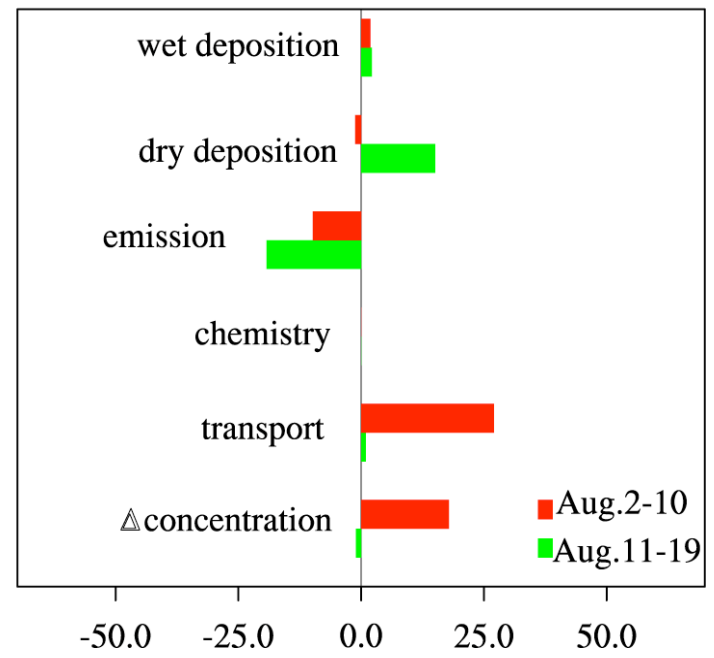

Fig. 6. (a) Budgets in July-August 2008 (blue) and (b) budget differences of the period 2-10 August (red) and 11-19 August (green) with July-August for BC over Beijing. $\Delta$-concentration denotes variation of concentration. The positive value denotes increase to concentration and the negative value denotes decrease to concentration over Beijing. Unit: ton day ${ }^{-1}$.

there are emission controls during the July-August period (e.g. $35 \%$ reduction after 20 July and $50 \%$ reduction during the Olympics in Beijing), the emission reduction for the 11-19 August period compared to the no-control case can be larger. Even so, however, the magnitude of transport loss $\left(26.9\right.$ ton day $\left.^{-1}\right)$ is still comparable to that of emission reduction.

From the above analysis, comparing with the average conditions in July and August in 2008, when meteorological conditions are not favorable (e.g. for the period of 2-10 August), BC concentration could still be high even though fullscale emission controls are enforced. On the other hand, when the meteorological conditions are favorable (for the period of 11-19 August), emission controls can be effective for decreasing the air pollutants in Beijing.

\section{Summary and conclusions}

To improving the air quality during the 2008 Beijing Olympic Games, emission control measures have been implemented by the City Government of Beijing. This provides a unique opportunity for examining the emission control policy on air quality in megacities. By using the fully coupled meteorology-chemistry model (WRF-Chem), we conducted several numerical experiments: NO-CTL, CTL, CTL-BJ0, CTL-RD0, and NO-CTL07 for the period of July to September in 2008 to investigate the factors contributing to the observed aerosol concentration reduction during the Olympic Games.
In general, the modeled results of $\mathrm{PM}_{2.5}$ and aerosol species concentrations in the CTL case during the Olympic Games can reproduce the observations, providing the basis of the following sensitivity analysis. During the Olympic period from 8 to 24 August 2008, aerosol species and $\mathrm{PM}_{2.5}$ concentrations were significantly reduced compared to the concentrations in the other periods from June to August in 2008: at the CMA site, $\mathrm{SO}_{4}, \mathrm{NH}_{4}, \mathrm{NH}_{4}, \mathrm{BC}$, and $\mathrm{OC}$ decreased by $35 \%-50 \%$, and at $\mathrm{T} 1, \mathrm{~T} 2, \mathrm{~T} 3$, and $\mathrm{T} 4$ sites of the Beijing-Tianjin-Hebei Atmospheric Environment Monitoring Network, $\mathrm{PM}_{2.5}$ decreased by about $30 \%-50 \%$. The model simulations also show that the $\mathrm{PM}_{2.5}, \mathrm{NH}_{4}, \mathrm{BC}$, and OC concentrations decreased by about $30 \%$ over Beijing due to emission controls. The reduction of $\mathrm{NO}_{3}$ and $\mathrm{SO}_{4}$ is about $40 \%$ and $20 \%$, respectively.

Although the mean aerosol concentrations are lower during the Olympic period, there are still occasional high $\mathrm{PM}_{2.5}$ concentrations (above $150 \mathrm{\mu g} \mathrm{m}^{-3}$ ) during the emission control. The meteorological condition is found to be the cause for the daily fluctuations of aerosol concentrations. Southerly winds are always associated with high concentrations and northeasterly winds with low concentrations. Southerly and southwesterly winds and low precipitation around 26 July and 4-9 August are the reasons for the high concentrations before the Olympic Games, while northeasterly winds on 1120 August and precipitation around 10 August contribute to the low concentrations during the Olympic period. The sensitivity simulations showed that the pollutant transport from the regions surrounding Beijing determines the fluctuation of $\mathrm{PM}_{2.5}$ concentrations. The emissions over the surrounding regions contribute more to the variation of Beijing $\mathrm{PM}_{2.5}$ 
concentrations than do the emissions over Beijing. Although emission controls result in a $\sim 30 \%$ reduction of particle concentrations, the air pollutants surrounding Beijing along with the unfavorable meteorological conditions contribute to the occasional high concentrations during the emission control.

Furthermore, the budget analysis shows that the contribution of emission, transport, and dry and wet deposition are $64.5,-27.9,-30.7$, and -10.3 ton day $^{-1}$ respectively to the $\mathrm{BC}$ burden, resulting in a reduction of -4.2 ton $\mathrm{day}^{-1}$ in July and August 2008. The budget difference between the period of 2-10 August and July-August shows that the ventilation effect of transport is weakened by 27.1 ton day ${ }^{-1}$, reflecting that the unfavorable transport is the main reason for the high aerosol concentrations on 2-10 August. On the other side, the budget difference between the period of 11-19 August and July-August shows that the emission control with favorable transport condition can effectively improve the air quality, particularly for particle matter, over Beijing. This study suggests that the emission control on regional scale is necessary in order to improve the air quality over Beijing. Since aerosol concentrations in Beijing are to a large extent, influenced by the surrounding areas when the southerly winds prevail with clear-sky conditions, it is critical to strength the emission control over the surrounding areas of Beijing (especially in the South) under these meteorological conditions. We concluded that in addition to emission controls meteorological conditions (e.g. wind direction and precipitation) were also important in producing the low aerosol concentrations appearing during the Olympic period. Emission controls decreased the average concentrations of aerosol species, while meteorological conditions were response for the daily fluctuations of aerosol concentrations during the Olympic Games.

There are uncertainties with the emissions used in our model simulations. First, some emission control measures started before 20 July 2008 (M. Wang et al., 2009), and the actual dates of emission control are different from what officially reported. However, in this study we focus our analysis on the period of August 2008 for the importance of meteorological conditions. Since aerosol has a lifetime of a few days in the lower atmosphere, the uncertainties with the actual dates of emission control will not change our conclusions. Second, there are uncertainties with the emission reductions in Beijing and in the provinces outside Beijing during the full-scale emission control period (i.e. after 20 July 2008). The model simulation in the CTL case has a positive bias during the Olympic period and for the period of July and August as indicated in Table 2 and Fig. 2, which may result from uncertainties in the emission estimations. However, our analysis in Fig. 3 depends on the relative difference of emissions used in the CTL and NO-CTL cases, rather than on the absolute emissions in each case (i.e. emission in the CTL case is estimated from that in the NO-CTL case). Likewise, analysis shown in Fig. 5 examines the anomaly of PM concentrations by subtracting the averaged concentration from its daily values for different cases (CTL, CTL-BJ0 and CTL-RD0) rather than the daily values to show the effect of transport on daily variations of PM concentration in Beijing. For the analysis shown in Fig. 6 we compare the BC budget differences between different time periods. Thus, although the absolute values of aerosol concentrations from each simulation can be impacted by the emission uncertainties, our conclusion regarding the role of meteorological conditions versus emission controls in determining the aerosol concentrations during the Olympics will not change.

\section{Supplementary material related to this article is available online at: http://www.atmos-chem-phys.net/11/12437/2011/ acp-11-12437-2011-supplement.pdf.}

Acknowledgements. X. Liu acknowledges the funding support from the US Department of Energy (DOE), Office of Science, Scientific Discovery through Advanced Computing (SciDAC) Program M. Zhang was funded by the National Natural Science Foundation of China (No. 20937001) and the National Department Public Benefit Research Foundation (Ministry of Environmental Protection of China) (No. 201009001 and 201109002). The Pacific Northwest National Laboratory is operated for DOE by Battelle Memorial Institute under contract DE-AC06-76RLO 1830.

Edited by: T. Zhu

\section{References}

Ackermann, I. J., Hass, H., Memmesheimer, M., Ebel, A., Binkowski, F. S., and Shankar, U.: Modal aerosol dynamics model for Europe: Development and first applications, Atmos. Environ., 32, 2981-2999, 1998.

An, X., Zhu, T., Wang, Z., Li, C., and Wang, Y.: A modeling analysis of a heavy air pollution episode occurred in Beijing, Atmos. Chem. Phys., 7, 3103-3114, doi:10.5194/acp-7-3103-2007, 2007.

Beijing Environmental Bulletin, 1994-2005, Beijing Municipal Environmental Protection Bureau, Beijing, http://www.bjepb.gov. cn/, last access: 11 November 2010.

Binkowski, F. S. and Shankar, U.: The regional particulate matter model, 1. mode desription and preliminary results, J. Geophys. Res., 100, 26191-26209, 1995.

Brown, J. F., Loveland, T. R., Merchant, J. W., Reed, B. C., and Ohlen, D. O.: Using multi-source data in global land-cover characterization: concepts, requirements, and methods, Photogram. Eng. Remote Sensing, 59, 977-987, 1993.

Cermak, J. and Knutti, R.: Beijing Olympics as an aerosol field experiment, Geophys. Res. Lett., 36, L10806, doi:10.1029/2009GL038572, 2009.

Chan, C. K. and Yao, X.: Air pollution in mega cities in China, Atmos. Environ., 42, 1-42, 2008.

Easter, R. C., Ghan, S. J., Zhang, Y., Saylor, R. D., Chapman, E. G., Laulainen, N. S., Abdul-Razzak, H., Leung, L. R., Bian, X., and Zaveri, R. A.: MIRAGE: Model Description and Evaluation 
of Aerosols and Trace Gases, J. Geophys. Res., 109, D20210, doi:10.1029/2004JD004571, 2004.

Fast, J. D, Gustafson Jr., W. I., Easter, R. C., Zaveri, R. A., Barnard, J. C., Chapman, E. G., and. Grell, G. A.: Evolution of ozone, particulates, and aerosol direct forcing in an urban area using a new fully-coupled meteorology, chemistry, and aerosol model, J. Geophys. Res., 111, D21305, doi:10.1029/2005JD006721, 2006.

Ghan, S., Laulainen, N., Easter, R., Wagener, R., Nemesure, S., Chapman, E., Zhang, Y., and Leung, R.: Evaluation of aerosol direct radiative forcing in MIRAGE, J. Geophys. Res., 106, 52955316, 2001.

Grell, G. A., Peckham, S. E., Schmitz, R., and McKeen, S. A., Frost, G., Skamarock, W. C., and Eder, B.: Fully coupled "online" chemistry within the WRF model, Atmos. Environ., 39, 69576976, 2005.

Guenther, A., Karl, T., Harley, P., Wiedinmyer, C., Palmer, P. I., and Geron, C.: Estimates of global terrestrial isoprene emissions using MEGAN (Model of Emissions of Gases and Aerosols from Nature), Atmos. Chem. Phys., 6, 3181-3210, doi:10.5194/acp-63181-2006, 2006.

Gustafson, W. I., Chapman, E. G., Ghan, S. J., Easter, R. C., and Fast, J. D.: Impact on modeled cloud characteristics due to simplified treatment of uniform cloud condensation nuclei during NEAQS 2004, Geophys. Res. Lett., 34, L19809, doi:10.1029/2007GL0300321, 2007.

Han, Z. W., Zhang, R. J., Wang, Q. G., Wang, W., Cao, J. J. and $\mathrm{Xu}, \mathrm{J} .:$ Regional Modeling of Organic Aerosols over China in summertime, J. Geophys. Res., 113, D11202, doi:10.1029/2007JD009436, 2008.

Hsu, K., Gao, X., Sorooshian, S., and Gupta, H. V.: Precipitation estimation from remotely sensed information using artificial neural networks., J. Appl. Meteorol., 36, 1176-1190, 1997.

Hsu, K., Gupta, H., Gao, X., and Sorooshian, S.: Estimation of physical variables from multi-channel remotely sensed imagery using a neural network: application to rainfall estimation., Water Resour. Res., 35, 1605-1618, 1999.

Kulmala, M., Laaksonen, A., and Pirjola, L.: Parameterizations for sulphuric acid/water nucleation rates, J. Geophys. Res., 103, 8301-8307, 1998.

Li, G., Zavala, M., Lei, W., Tsimpidi, A. P., Karydis, V. A., Pandis, S. N., Canagaratna, M. R., and Molina, L. T.: Simulations of organic aerosol concentrations in Mexico City using the WRFCHEM model during the MCMA-2006/MILAGRO campaign, Atmos. Chem. Phys., 11, 3789-3809, doi:10.5194/acp-11-37892011, 2011.

Loveland, T. R., Merchant, J. W., Ohlen, D. O., and Brown, J. F.: Development of a land-cover characteristics database for the conterminous US Photogram, Eng. Remote Sens., 57, 1453-1463. 1991.

McKeen, S. A., Wotawa, G., Parrish, D. D., Holloway, J. S., Buhr, M. P., Hubler, G., Fehsenfeld, F. C., and Meagher, J. F.: Ozone production from Canadian wildfires during June and July of 1995, J. Geophys. Res., 107, 4192, doi:10.1029/2001JD000697, 2002.

Randerson, J. T., Van der Werf, G. R., Giglio, L., Collatz, G. J., and Kasibhatla, P. S.: Global Fire Emissions Database, Version 2 (GFEDv2. 1), Available at: http://daac.ornl.gov/ from Oak Ridge National Laboratory Distributed Active Archive Center, Oak Ridge, Tennesse, USA, doi:10.3334/ORNLDAAC/849, last access: 14 July 2010.

Schell, B., Ackermann, I. J., Hass, H., Binkowski, F. S., and Ebel, A.: Modeling the formation of secondary organic aerosol within a comprehensive air quality modeling system, J. Geophys. Res., 106, 28275-28293, 2001.

Shrivastava, M., Fast, J., Easter, R., Gustafson Jr., W. I., Zaveri, R. A., Jimenez, J. L., Saide, P., and Hodzic, A.: Modeling organic aerosols in a megacity: comparison of simple and complex representations of the volatility basis set approach, Atmos. Chem. Phys., 11, 6639-6662, doi:10.5194/acp-11-6639-2011, 2011.

Sorooshian, S., Hsu, K., Gao, X., Gupta, H., Imam, B., and Braithwaite, D.: Evaluation of PERSIANN system satellite-based estimates of tropical rainfall., B. Am. Meteorol. Soc., 81, 20352046, 2000.

Stauffer, D. R. and Seaman, N. L.: Use of four-dimensional data assimilation in a limited-area mesoscale model, Part I: Experiments with synoptic-scale data, Mon. Weather Rev., 118, 1250-1277, 1990.

Stauffer, D. R., Seaman, N. L., and Binkowski, F. S.: Use of fourdimensional data assimilation in a limited-area mesoscale model, Part II: Effects of data assimilation within the planetary boundary layer, Mon. Weather Rev., 119, 734-754, 1991.

Stauffer, D. R. and Seaman, N. L.: Multi-scale four-dimensional data assimilation, J. Appl. Meteorol., 33, 416-434, 1994.

Stockwell, W. R., Middleton, P., Chang, J. S., and Tang, X.: The second generation regional acid deposition model chemical mechanism for regional air quality modeling, J. Geophys. Res., 95, 16343-16367, 1990.

Streets, D. G., Fu, J. H. S., Jang, C. J., Hao, J. M., He, K. B., Tang, X. Y., Zhang, Y. H., Wang, Z. F., Li, Z. P., Zhang, Q., Wang, L. T., Wang, B. Y., and Yu, C.: Air quality during the 2008 Beijing Olympic Games, Atmos. Environ., 41, 480-492, 2007.

Tang, Y., Carmichael, G. R., Seinfeld, J. H., Dabdub, D., Weber, R. J., Huebert, B., Clarke, A. D., Guazzotti, S. A., Sodeman, D. A., Prather, K. A., Uno, I., Woo, J.-H., Streets, D. G., Quinn, P. K., Johnson, J. E., Song, C.-H., Sandu, A., Talbot, R. W., and Dibb, J. E.: Three-dimensional simulations of inorganic aerosol distributions in east Asia during spring 2001, J. Geophys. Res., 109, D19S23, doi:10.1029/2003JD004201, 2004.

Wang, M., Zhu, T., Zheng, J., Zhang, R. Y., Zhang, S. Q., Xie, X. X., Han, Y. Q., and Li, Y.: Use of a mobile laboratory to evaluate changes in on-road air pollutants during the Beijing 2008 Summer Olympics, Atmos. Chem. Phys., 9, 8247-8263, doi:10.5194/acp-9-8247-2009, 2009.

Wang, S., Zhao, M., Xing, J., Wu, Y., Zhou, Y., Lei, Y., He, K., $\mathrm{Fu}$, L., and Hao, J.: Quantifying the air pollutants emission reduction during the 2008 Olympic games in Beijing, Environ. Sci. Technol., 44, 2490-2496, 2010.

Wang, T. and Xie, S. D.: Assessment of traffic-related air pollution in the urban streets before and during the 2008 Beijing Olympic Games traffic control period, Atmos. Environ., 43, 5682-5690, 2009.

Wang, T., Nie, W., Gao, J., Xue, L. K., Gao, X. M., Wang, X. F., Qiu, J., Poon, C. N., Meinardi, S., Blake, D., Wang, S. L., Ding, A. J., Chai, F. H., Zhang, Q. Z., and Wang, W. X.: Air quality during the 2008 Beijing Olympics: secondary pollutants and regional impact, Atmos. Chem. Phys., 10, 7603-7615, doi:10.5194/acp-10-7603-2010, 2010.

Wang, Y., Hao, J., McElroy, M. B., Munger, J. W., Ma, H., Chen, 
D., and Nielsen, C. P.: Ozone air quality during the 2008 Beijing Olympics: effectiveness of emission restrictions, Atmos. Chem. Phys., 9, 5237-5251, doi:10.5194/acp-9-5237-2009, 2009.

Wesley, M. L.: Parameterization of surface resistance to gaseous dry deposition in regional numerical models, Atmos. Environ., 16, 1293-1304, 1989.

Whitby, E. R., McMurry, P. H., Shankar, U., and Binkowski, F. S.: Modal aerosol dynamics modeling, Rep. 600/3-91/020, Atmospheric Research and Exposure Assessment Laboratory, US Environmental Protection Agency, Research Triangle Park, NC, 1991 (Available as NTIS PB91-1617291AS from National Technical Information Service, Springfield, VA, USA), 1991.

Xin, J. Y., Wang, Y. S., Tang, G. Q., Wang, L. L., Sun, Y., Wang, Y. H., Hu, B., Song, T., Ji, D. S., Wang, W. F., Li, L., and Liu, G. R.: Variability and reduction of atmospheric pollutants in Beijing and its surrounding area during the Beijing 2008 Olympic Games, Chinese Sci. Bull., 55, 1937-1944, doi:10.1007/s11434010-3216-2, 2010.

Yang, Q., Wang, Y., Zhao, C., Liu, Z., Gustafson, Jr., W. I., and Shao M.: NOx emission reduction and its effects on ozone during the 2008 Olympic Games, Environ. Sci. Technol., 45, 6404-6410, 2011.

Zaveri, R. A. and Peters, L. K.: A new lumped structure photochemical mechanism for large-scale applications, J. Geophys. Res., 104, 30387-30415, 1999.

Zaveri, R. A., Easter, R. C., Fast, J. D., and Peters, L. K.: Model for simulating aerosol interactions and chemistry (MOSAIC), J. Geophys. Res., 113, D13204, doi:10.1029/2007JD008792, 2008.
Zhang, Q., Streets, D. G., Carmichael, G. R., He, K. B., Huo, H., Kannari, A., Klimont, Z., Park, I. S., Reddy, S., Fu, J. S., Chen, D., Duan, L., Lei, Y., Wang, L. T., and Yao, Z. L.: Asian emissions in 2006 for the NASA INTEX-B mission, Atmos. Chem. Phys., 9, 5131-5153, doi:10.5194/acp-9-5131-2009, 2009.

Zhang, X. Y., Wang, Y. Q., Lin, W. L., Zhang, Y. M., Zhang, X. C., Gong, S., Zhao, P., Yang, Y. Q., Wang, J. Z., and Hou, Q.: Changes of Atmospheric Composition and Optical Properties Over BEIJING-2008 Olympic Monitoring Campaign, B. Am. Meteorol. Soc., 90, 1633-1651, 2009.

Zhao, C., Liu, X., Leung, L. R., Johnson, B., McFarlane, S. A., Gustafson Jr., W. I., Fast, J. D., and Easter, R.: The spatial distribution of mineral dust and its shortwave radiative forcing over North Africa: modeling sensitivities to dust emissions and aerosol size treatments, Atmos. Chem. Phys., 10, 8821-8838, doi:10.5194/acp-10-8821-2010, 2010a.

Zhao, C., Wang, Y., Yang, Q., Fu, R., and Choi, Y.: Impact of East Asia summer monsoon on the air quality over China: The view from space, J. Geophys. Res., 115, D09301, doi:10.1029/2009JD012745, 2010b.

Zhao, C., Liu, X., Ruby Leung, L., and Hagos, S.: Radiative impact of mineral dust on monsoon precipitation variability over West Africa, Atmos. Chem. Phys., 11, 1879-1893, doi:10.5194/acp11-1879-2011, 2011. 